\title{
EFFECT OF PREPARATION PARAMETERS ON LIGHT SENSITIVITY IN SUPERCONDUCTIVE TUNNEL JUNCTIONS
}

\author{
A. BARONE, P. RISSMAN (*) and M. RUSSO \\ Laboratorio di Cibernetica del CNR, Via Toiano 2, Arco Felice, Napoli, Italy
}

\begin{abstract}
Résumé. - Des jonctions « tunnel » supraconductrices utilisant du sulfure de cadmium et du séléniure de cadmium comme barrière sont étudiées expérimentalement. Ces dispositifs sont sensibles à un rayonnement lumineux. On donne les résultats concernant la photo-sensibilité des jonctions qui présentent soit l'effet Josephson, soit l'effet tunnel de quasi-particules. On discute les caractéristiques des échantillons étudiés en fonction des conditions de préparation.

Abstract. - Superconductive tunnel junctions which employ cadmium sulphide and cadmium selenide layers as tunneling barrier have been experimentally investigated. These structures exhibit a light-sensitive behaviour. Results concerning photoresponse of both Josephson and quasiparticle tunneling junctions are reported. Physical parameters of preparation in connection with the resulting characteristics of the samples are discussed.
\end{abstract}

1. Introduction. - Since the first experiments reported by Giaever [1] on light sensitive tunnel junctions there has been great interest in the investigation of such structures from both the experimental [2]-[4] and theoretical point of view [2], [5]. The effect of the external magnetic field on the maximum Josephson current has been experimentally investigated for these junctions by Dynes and Fulton [6]. Investigation of structures which employ semiconductor layers as tunneling barriers, independent of photosensitive effects, has been performed by many Authors [6]-[16]. Cardinne et al. [17] have considered semiconductor barriers for low capacitance tunnel junctions.

Light-sensitive semiconductors provide the possibility of making superconductive tunnel junctions with an " adjustable " barrier height. Also the possibility of having optically controlled components represents a stimulating objective.

Following preliminary investigations performed in this Laboratory [18], a great deal of experimental work has been concentrated on junctions which employ CdS as tunnel barrier. Furthermore, the success of the use of CdSe in such structures [14] and the demonstration that it could be a photosensitive barrier [19], suggested also this material for experimentation. The connection between the physical parameters of preparation and the resulting characteristics of the samples is discussed in the next section. In section 3 data concerning the photosensitive behaviour of both quasiparticle and Josephson tunneling structures are reported. An investigation

(*) On research leave from the University of Wisconsin, Madison, Wisconsin, USA. of the spectral response of these devices has also been initiated and preliminary results concerning the dependence of the tunneling current as function of the light exposure time are given.

2. Effects of preparation parameters on junction characteristics. - A large number of superconductive junctions employing $\mathrm{CdS}$ as semiconducting tunneling barrier has been made; different aspects in the $V$-I characteristics of such structures can be connected with variations in preparation parameters. In addition, junctions with CdSe barriers have been made. Films of CdSe can be more easily prepared than those of CdS [20], [21]. Cadmium selenide films can be deposited in ultra high vacuum systems without fear of contamination. Work with these junctions is just beginning but initial data are promising.

2.1 CdS BARRIER JUNCTIONS. - The junctions preparation followed conventional methods [1]-[4]. After the evaporation of the first superconducting layer $(\mathrm{Pb}$ or $\mathrm{Sn})$, the cadmium sulphide (high purity powder, Alfa Inorganics) was evaporated onto glass microscope slides at room temperature. Before the deposition, the semiconductor was pre-heated for about $10 \mathrm{mn}$. During the evaporation the turbo pump system pressure was about 6-8 $\times 10^{-6}$ torr. The deposition rate was approximately $5 \AA \mathrm{s}^{-1}$. Then, dry air was introduced into the vacuum chamber and the sample was allowed to oxidize for $1 \mathrm{~h}$ at a pressure of $1 \mathrm{~atm}$. This step is sufficient to prevent the presence of pin-holes in the sample [14]. Finally, the top superconducting electrode was deposited. All the CdS junctions considered in this work have a cross geometry with an area of about $1.7 \mathrm{~mm}^{2}$. 
During the preparation many factors contribute to the opto-electronic characteristics of the structures. A wide range of tunnel resistance values has been obtained by changing the CdS layer thickness $(t)$ and pressure during the semiconductor deposition.

The "dark " resistance range for symmetric structures $(\mathrm{Pb}-\mathrm{CdS}-\mathrm{Pb})$ covers from $10^{4}$ to $10^{-1} \Omega$. For asymmetrical junctions ( $\mathrm{Pb}-\mathrm{CdS}-\mathrm{Sn})$, due to the fabrication problems, only a narrow range of values $(\lesssim 10 \Omega$ ) has been obtained.

Influence of the barrier thickness is shown in figure 1. From the figure it is possible to observe decreasing values of the tunnel resistance from about $100 \Omega$ to $0.7 \Omega$ as the CdS thickness is reduced from $t \gtrsim 500 \AA$ to about $100 \AA$. Quasiparticle tunneling between superconductors ( $V-I$ characteristics displaying a clear superconductive band gap structure) occurs only for $t \lesssim 500 \AA$; for $t<150 \AA$ the dc Josephson effect appears.

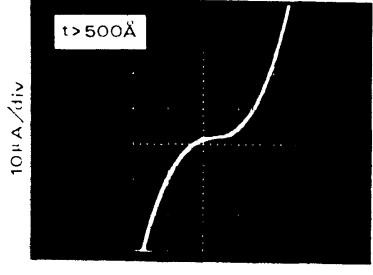

$5 m v / d i v$

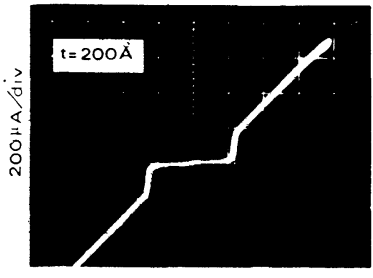

$2 m V / d ı v$

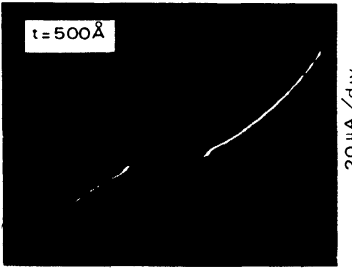

$2 m v / d i v$

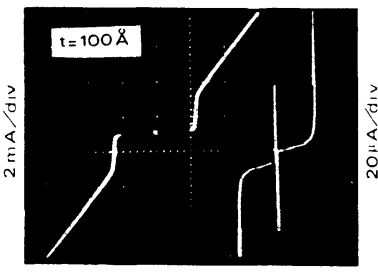

$2 m V / d i v$
FIG. 1. - Effect of the semiconductor thickness on the $V-I$ characteristics at $4.2 \mathrm{~K}$ of $\mathrm{Pb}-\mathrm{CdS}-\mathrm{Pb}$ samples. All junctions have the same area.

The influence of the pressure during the evaporation is critical. In fact, generally, higher pressure (up to $2 \times 10^{-5}$ torr) causes a lower film resistance. In addition, some other conduction mechanisms can be involved since a greater amount of spurious current is present and the $V-I$ characteristics become asymmetric. The last effect is very well observable for the thicker CdS layers. Asymmetry in $V-I$ characteristics has been also observed by Lubberts and Shapiro [14] in connection with the temperature of the substrate. Because of the difference in the vapour pressure of cadmium and sulfur [22], films of different characteristics can be obtained. This is due to different percentage of cadmium [23], [24] and, probably, to a variation in the amount of trapped $\mathrm{O}_{2}$. In figure 2 are shown the $V-I$ characteristics of two junctions exhibiting about the same tunnel resistance with different semiconductor barrier thicknesses. This is probably due to differences in the potential barrier shape and height. Present work deals with junctions of the second type because they exhibit a more pronounced light sensitive behaviour.

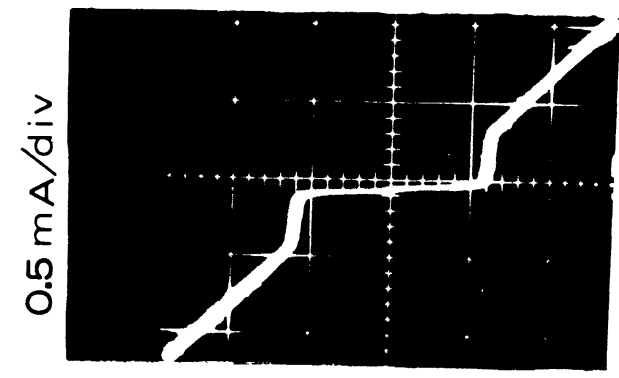

$2 m v / d i v$

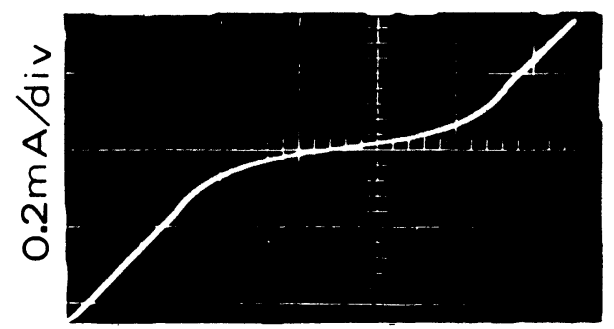

$1.3 \mathrm{~m} \mathrm{~V} / \mathrm{div}$

FIG. 2. - $V-I$ characteristics at $4.2 \mathrm{~K}$ of two $\mathrm{Pb}-\mathrm{CdS}-\mathrm{Pb}$ junctions having equal area, about the same tunnel resistance but different barrier thicknesses $\left(t_{1} \simeq 100 \AA, t_{2} \simeq 200 \AA\right)$.

2.2 CdSe BARRIER JUNCTIONS. - Junctions which employed niobium as the base layer were made following the procedure of Hoel et al. [25].

After the niobium film was prepared and sputter cleaned, CdSe powder (Alfa Inorganics « ultrapure ») was evaporated from an aluminium oxide crucible onto room temperature substrates. The evaporant was carefully degassed and the pressure in the oil diffusion pump system was held below $2 \times 10^{-6}$ torr. Evaporation rate, measured with a quartz crystal thickness monitor, was approximately $5 \AA \mathrm{s}^{-1}$. Typical junction barrier thickness was $50 \AA$. An oxidation step (see discussion below) was then performed and a top lead layer (crossed strip geometry) evaporated. $\mathrm{Pb}-\mathrm{CdSe}-\mathrm{Pb}$ and $\mathrm{Sn}-\mathrm{CdSe}-\mathrm{Sn}$ junctions were fabricated in an Ultek ion pump-system. This afforded the possibility of maintaining the system pressure below $1 \times 10^{-7}$ torr during the semiconductor evaporation. CdSe was evaporated from a covered molybdenum canoe boat. As before, after an oxidation step, the top layer was evaporated. Junctions with semiconductor barriers have always been oxidized to close pinholes, either by thermal oxidation [1], [11], [13], [16], [18] or by plasma oxidation [14]. The samples with CdSe barriers prepared in this study were subjected to a plasma oxidation step [26]. Because it was expected that the high energy of the 
oxygen ions could affect the properties of the semiconductor, a shim mask was arranged such that junctions could be shielded from the plasma. In this way, junctions on the same substrate could be subjected to different oxidation times or, in fact, shielded entirely from the glow discharge. The plasma was formed in a pure oxygen at 20 mtorr with an ionizing voltage at $0.5-1.0 \mathrm{kV}$. The oxidation time was varied from 0 to $15 \mathrm{mn}$. The junctions shielded from the plasma, indicated in table I as « no oxidation ", were probably somewhat oxidized either thermally or due to imperfection of the shielding. These shielded junctions, for all three base metals $(\mathrm{Nb}, \mathrm{Sn}$, $\mathrm{Pb}$ ) exhibited the strongest photosensitivity. The effect of the oxidation was found to decrease the photosensitivity and increase the impedance, as is shown in figure 3 , for junctions with the same barrier thickness on the same substrate. Many junctions strongly oxidized were shorted indicating damage to the semiconductor layer. It will be interesting to try fabricating junctions avoiding any oxidation. Typical preparation parameters and results are summarized in table $\mathrm{I}$.

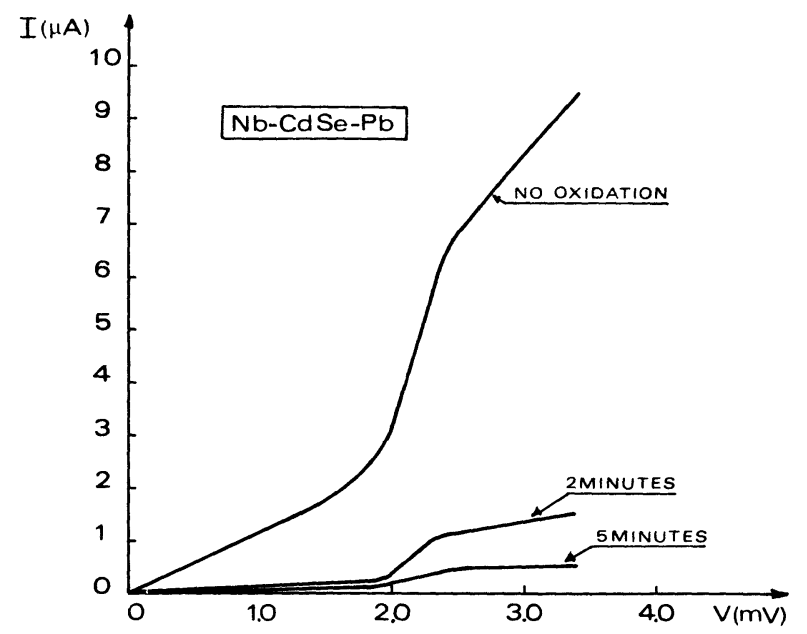

Fig. 3. - Dark V-I characteristics at $4.2 \mathrm{~K}$ of $\mathrm{Nb}-\mathrm{CdSe}-\mathrm{Pb}$ samples showing the effect of the oxidation time on the junction impedance.
3. Light sensitivity. - Due to the photosensitive character of CdS and CdSe films [27], a light input on the junctions causes a modification in their barrier characteristics. This leads to a decrease of the tunnel resistance of the samples as shown in figures 4,5 . Giaever [2] has given a possible explanation of the light sensitivity of these junctions which has been further discussed by Radhakrishnan [5]. This model is based on an effective barrier lowering due to trap state for photoholes. These traps have an extremely long recombination time [28] which leads to a conductivity storage effect. For the junctions discussed here, in fact, the tunnel resistance change is permanent for experimental times of several hours. To reset the junctions to their original state it is necessary either to pulse them with a high current or to warm them up to above $100 \mathrm{~K}$. A combination of storage and non-storage photocurrents has been also observed in a few samples. In the $\mathrm{CdS}$ junctions such behaviour appeared to be connected with higher evaporation pressures (see section 2.1). The largest measured change of the tunneling current for both $\mathrm{CdS}$ and $\mathrm{CdSe}$ junctions was of the order of $10^{3}$. This value is not necessarily the maximum since longer exposure times or optimization of the reset could lead to even greater factors of change.

When the semiconductor layer is thinner (lower effective barrier height), Josephson current can be induced by light exposure. This effect, in $\mathrm{Pb}-\mathrm{CdS}-\mathrm{Pb}$ junction, is shown in figure $4 c, d$. The $V-I$ characteristics clearly exhibit an half gap bump. For such structures the dark tunnel resistance is below $10 \Omega$ $(t \leqslant 150 \AA)$.

Initially the Josephson current, $I_{\mathrm{J}}$, increases with the duration of the optical input. For longer values of light exposure, however, no further increase in $I_{\mathrm{J}}$ has been observed although the quasiparticle branch continued to be modified. This saturation could be associated with, among other reasons, self-field limiting.

Josephson current has not been light induced or modified, to present, on any CdSe samples. The $V-I$ characteristic of a photosensitive $\mathrm{Pb}-\mathrm{CdSe}-\mathrm{Pb}$ junction

TABLE I

\section{Junction preparation}

\begin{tabular}{|c|c|c|c|c|}
\hline Type of junction & 1st S. C. Layer & $\begin{array}{l}\text { Semiconductor } \\
\text { evaporation }\left(^{1}\right)\end{array}$ & Oxidation & 2nd S. C. Layer \\
\hline $\mathrm{Pb}-\mathrm{CdS}-\mathrm{Pb}$ & Evaporated & $10^{-6}$ torr $(\mathrm{TMP})\left(^{2}\right)$ & Air $(\sim 1 \mathrm{~atm})$ & Evaporated \\
\hline $\mathrm{Pb}-\mathrm{CdS}-\mathrm{Sn}$ & Evaporated & $10^{-6}$ torr (TMP) & $\operatorname{Air}(\sim 1 \mathrm{~atm})$ & \\
\hline $\mathrm{Nb}-\mathrm{CdSe}-\mathrm{Pb}$ & Sputtered & $10^{-6}$ torr (ODP) & & \\
\hline Sn-CdSe-Sn & Evaporated & $10^{-7}$ torr (IP) & Plasma ux & \\
\hline $\mathrm{Pb}-\mathrm{CdSe}-\mathrm{Pb}$ & Evaporated & $10^{-7}$ torr (IP) & & \\
\hline
\end{tabular}

( $\left.{ }^{1}\right)$ Semiconductor barrier thicknesses were in the range of 50-500 $\AA$.

$\left({ }^{2}\right)$ TMP turbo molecular pump

ODP oil diffusion pump

IP ion pump. 

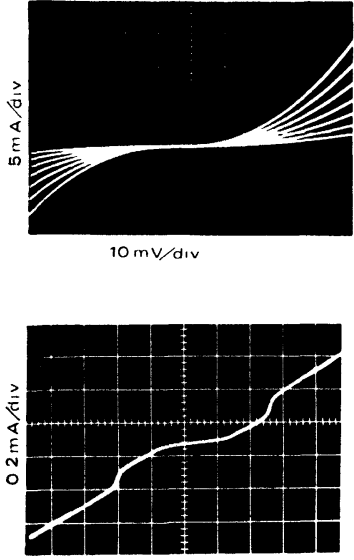

$1 \mathrm{mv} / \mathrm{div}$

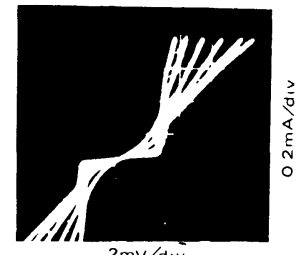

$2 m v / d v$

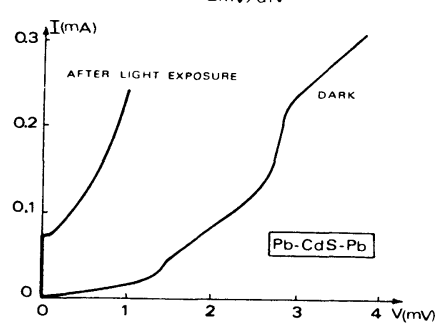

Fig. 4. - Optical response of $\mathrm{Pb}-\mathrm{CdS}-\mathrm{Pb}$ junctions. All $V-I$ characteristics are at $4.2 \mathrm{~K}$; the optical input is realized by an electronic flash.

a) Light induced resistance change on a structure with $t>500 \AA$.

b) Light-sensitive quasiparticle tunneling.

c) Dark $V-I$ characteristic of a low impedance junction.

d) Light induced Josephson effect in the junction shown in $c$.

with an appreciable Josephson current is reported in figure 5. The zero-voltage current was present in the dark $V-I$ characteristic and for this reason the "yes » in table II is conditional. No explanation of this result can be made until the ratio of the current through the oxidized pin-holes to the actual current tunneling through the semiconductor is determined. The $\mathrm{Nb}$ $\mathrm{CdSe}-\mathrm{Pb}$ and $\mathrm{Sn}-\mathrm{CdSe}-\mathrm{Sn}$ junctions which exhibited light-sensitive behaviour in quasiparticle tunneling did not show Josephson current.

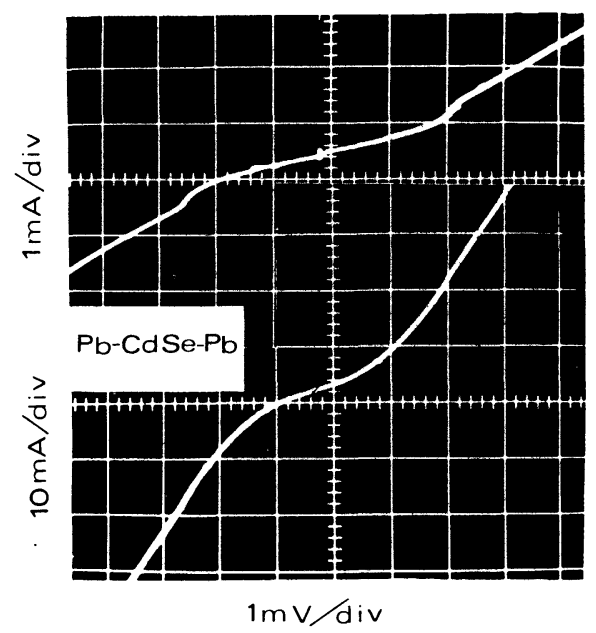

FIG. 5. - Tunnel resistance lowering due to light input on a $\mathrm{Pb}-\mathrm{CdSe}-\mathrm{Pb}$ junction at $4.2 \mathrm{~K}$.

Measurements of junction response to different light frequencies have been performed with several narrow band filters (typical half width $100 \AA$ ) in the range of 4000 to $9800 \AA$. For CdSe junctions there was a strong decrease in photosensitivity at energies approximately below that of the semiconductor band

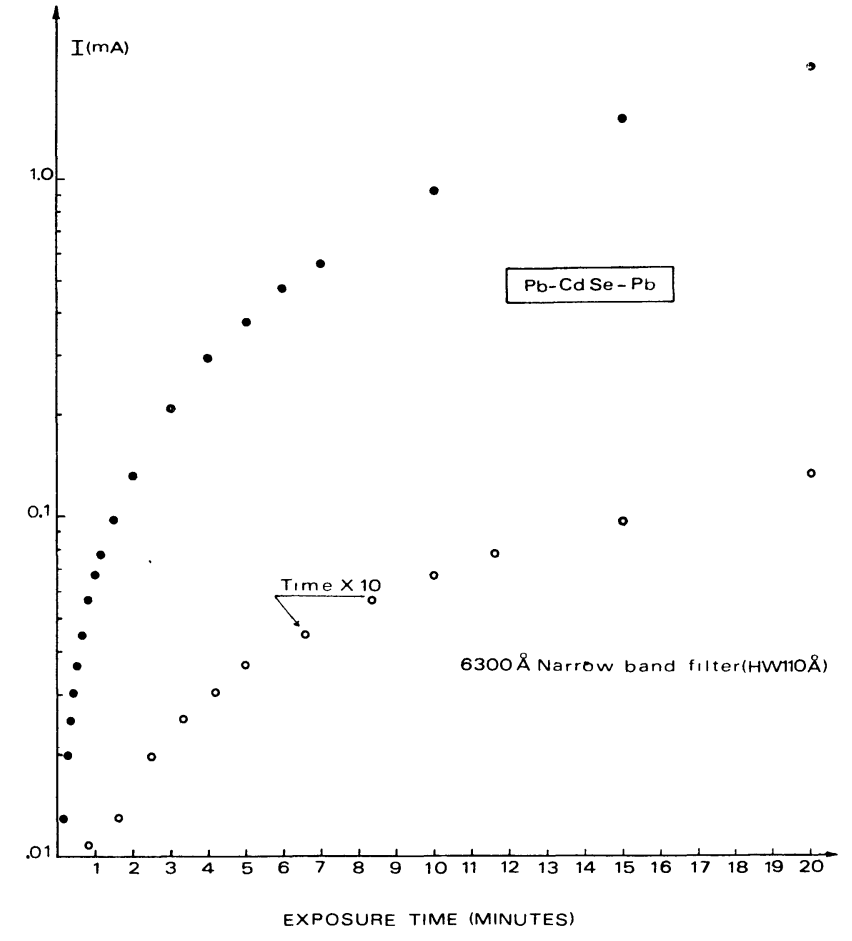

FIg. 6. - Light response with time exposure for a $\mathrm{Pb}-\mathrm{CdSe}-\mathrm{Pb}$ structure at $4.2 \mathrm{~K}$.

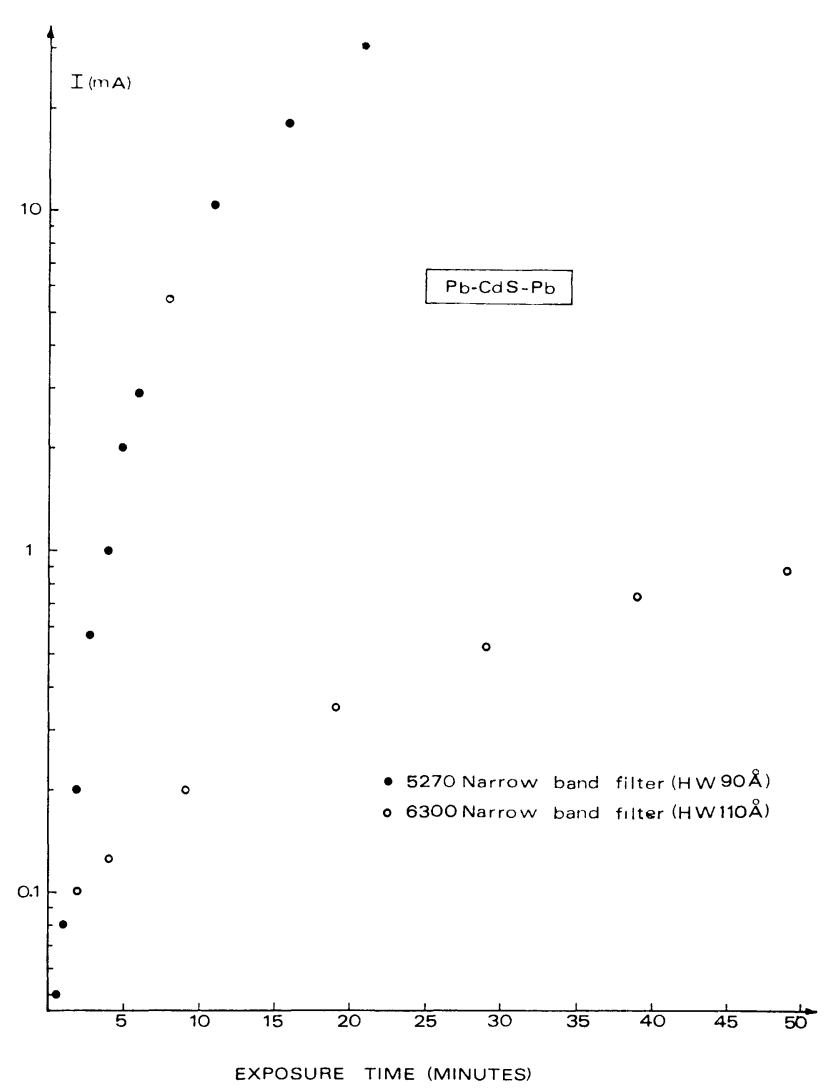

FIG. 7. - Light response with time exposure for a Pb-CdS-Pb structure at $4.2 \mathrm{~K}$. The curves for two different light frequencies are shown. 
TABLE II

Measured characteristics of light sensitive junctions

Type of junction
$\mathrm{Pb}-\mathrm{CdS}-\mathrm{Pb}$
$\mathrm{Pb}-\mathrm{CdS}-\mathrm{Sn}$
$\mathrm{Nb}-\mathrm{CdSe}-\mathrm{Pb}$
$\mathrm{Sn}-\mathrm{CdSe}-\mathrm{Sn}$
$\mathrm{Pb}-\mathrm{CdSe}-\mathrm{Pb}$

(*) See text.

Max observed
$R_{\text {DARK }} / R_{\text {LIGHT }}$
-
$10^{3}$
10
$10^{2}$
10
$10^{3}$

Josephson current
observed
Yes
Yes
No
No
Yes (*) gap. For CdS structures a wide maximum near the band gap value [29] and a cut-off at about $8000 \AA$ were observed.

Photoresponse of $\mathrm{Pb}-\mathrm{CdSe}-\mathrm{Pb}$ junction as a function of exposure time with $6300 \AA$ radiation is shown in figure 6 [30]. The same curve plotted for $\mathrm{Pb}-\mathrm{CdS}-\mathrm{Pb}$ with light input of $6300 \AA$ and $5270 \AA$ is reported in figure 7. These results can be useful for the realization of possible devices with optical input, although they are not suitable, at this stage of research, for a satisfactory physical interpretation. The results for light-sensitive superconducting tunnel junctions are summarized in table II.
Conclusion. - Results on the light-sensitive behaviour of a large number of superconductive junctions have been reported. Cadmium sulphide and cadmium selenide have been employed as semiconductor tunneling barriers. Various superconductor materials for electrodes have been used. The photoresponse of Josephson and quasiparticle tunneling structure has been investigated in connection with the physical parameters of the preparation procedures.

Acknowledgments. - The authors would like to thank C. Salinas and S. Piantedosi for help in preparation of data.

\section{References}

[1] Giaever, I., Phys. Rev. Lett. 20 (1968) 1286.

[2] Giaever, I. and Zeller, H. R., J. Vac. Sci. Tech. 6 (1969) 502.

[3] Giaever, I. and Zeller, H. R., Phys, Rev. B 1 (1970) 4278.

[4] Giaever, I. and Zeller, H. R., Physica 55 (1971) 455.

[5] Radhakrishnan, V., Can. J. Phys. 48 (1970) 630.

[6] Dynes, R. C. and Fulton, T. A., Phys. Rev. B 3 (1971) 3015.

[7] Macvicar, M. L. A., Freake, S. M. and Adkins, C. J., J. Vac. Sci. Tech. 6 (1969) 717.

[8] Macvicar, M. L. A., J. Appl. Phys. 41 (1970) 4765.

[9] Lipson, S. G. and Stupel, M. M., Phys. Lett. 33A (1970) 493.

[10] Cardinne, P., Marti, M. and Renard, M., Revue Phys. Appl. 6 (1971) 547.

[11] Seto, J. and Van Duzer, Appl. Phys. Lett. 19 (1971) 488.

[12] Keller, W. H. and Nordman, J. E., J. Appl. Phys. 42 (1971) 137

[13] Cardinne, P., Manhes, B. and Renard, M., Applied Superconductivity Conference, Annapolis, Maryland, May 1-3, 1972, (IEEE Press, New York) 1972, p. 565.

[14] Lubberts, G. and Shapiro, S., J. Appl. Phys. 43 (1972) 3958.

[15] Josefowicz, J. and Smith, H. J. T., J. Appl. Phys. 44 (1973) 2813.

[16] Keller, W. H. and Nordman, J. E. (to be published).
[17] Cardinne, P., Nordman, J. E. and Renard, M., Revue Phys. Appl. 9 (1974) 167.

[18] Russo, M., Atti Congresso Cibernetica Casciana Terme (GRC, Pisa) 1971, p. 424.

[19] Rissman, P., J. Appl. Phys. 44 (1973) 1893.

[20] De Klerk, J. and Kelley, E. F., Rev. Sci. Instrum. 36 (1965) 506.

[21] Gunther, K.-G., The Use of Thin Films in Physical Investigations, (Anderson, J. C. Ed. Academic, London) 1965, p. 224.

[22] Honig, R., RCA. Rev. 23 (1962) 567.

[23] Chopra, K. L., Thin Film Phenomena, (McGraw-Hill, New York) 1962, p. 452.

[24] Somorjai, G. A., J. Phys. and Chem. Solids 24 (1963) 175.

[25] Hoel, L. S., Keller, W. H., Nordman, J. E. and ScotT, A. C., Solid State Electron. 15 (1972) 1167.

[26] Barone, A. and Johnson, W. J. Vuoto Sci. Tec. 2 (1969) 215.

[27] Bube, R. H., Photoconductivity of Solids (Wiley, New York) 1963, p. 158.

[28] Bube, R. H., op. cit., p. 273.

[29] BUBE, R. H., op. cit., p. 233.

[30] In figure 6 the plotted current is the total value. A similar curve is obtained when the spurious current is subtracted and only the tunnel current is plotted, as is done in figure 7 . 